\title{
Preparatory process reflected in seismicity-pattern change preceding the $M=7$ earthquakes off Miyagi prefecture, Japan
}

\author{
Shozo Matsumura \\ National Research Institute for Earth Science and Disaster Prevention, Tennodai 3-1, Tsukuba, Ibaraki 305-0006, Japan
}

(Received December 16, 2005; Revised March 14, 2006; Accepted May 6, 2006; Online published February 2, 2007)

\begin{abstract}
Two M=7 interplate earthquakes recently occurred off Miyagi prefecture, northeastern Japan. These belong to a new sequence of earthquake series. The occurrence of this sequence was forewarned by the government, based primarily on a statistical approach utilizing historical records. Such a process, however, does not account for the present on-going status in the assessment. During the stage when stress approaches a critical level, there is a possibility of stress redistribution caused by a quasi-static slip, which will be reflected in a temporal change in seismic activity. Delineating a spatial map of the seismic-activity rate changes in the seismogenic zone off Miyagi prefecture, we found that there was an activation of microseismicity in the rupture zones several months prior to both $\mathrm{M}=7$ earthquakes. This was interpreted as evidence of a preparatory process preceding each $\mathrm{M=7}$ earthquake, during which a quasi-static slip progressed, driving stress redistribution and resulting in stress concentration on asperities of these earthquakes.
\end{abstract}

Key words: Microseismicity, stress redistribution, asperity, preparatory process.

\section{Introduction}

A major earthquake of $M=7.2$ occurred off Miyagi Prefecture in northeastern Japan on 16 August 2005 (arrow in Fig. 1). The region had been assigned the highest probability among many potential target candidates for major earthquakes in Japan by a government committee, which had issued an announcement that an $\mathrm{M}=7.5$ earthquake would occur with a probability of greater than $99 \%$ during the upcoming 30 years (Earthquake Research Committee, 2005a). The conclusion was based on a fundamental acceptance of periodic occurrences of characteristic earthquakes. Figure 1 illustrates the epicenter distribution and time sequence of major earthquakes since 1885, based on the Utsu and the Japan Meteorological Agency (JMA) catalogues. Earthquakes of $M=6.8$ and greater that occurred on the plate boundary and within the upper layer between double-layered activities within the subducted Pacific slab are sampled. There is a quasi-periodicity in the time sequence, with a recurrence interval of about 21 years for all of the sequences, and about 36 years for the larger earthquakes of $M=7.2$ and greater (marked with large solid circles). The earthquakes in the latter sequence are located almost at the same place, as shown in the figure. These were categorized as thrust-type interplate earthquakes, similar to those that ruptured an identical asperity between the Pacific and the North American plates (Yamanaka and Kikuchi, 2004). The government committee estimated the occurrence probability by referring to the sequence of the largest earthquakes of $M=7.4$ and greater with a mean interval of 37.1 years (e.g. Seno, 1979), the latest of which were the

Copyright (c) The Society of Geomagnetism and Earth, Planetary and Space Sciences (SGEPSS); The Seismological Society of Japan; The Volcanological Society of Japan; The Geodetic Society of Japan; The Japanese Society for Planetary Sciences; TERRAPUB
$M=7.4$ earthquake in 1936 and the $M=7.4$ earthquake in 1978. The occurrence of the $M=7.2$ earthquake in 2005 was once considered to be the predicted event but has been ultimately assessed as not being that event because of its insufficient magnitude. Thus, the problem still remains of a major earthquake off Miyagi Prefecture (Earthquake Research Committee, 2005b).

In the assessment of occurrence probability, none of the observed information is taken into account, with the exception of statistical evidence of the periodic occurrences. This approach is based on a consideration that in a probabilistic process, an individual occurrence within a sequence is occasional rather than deterministic. However, it is commonly understood that earthquake occurrences are generally ruled by some physical processes related to stress transfer. A typical case is the process of an earthquake triggering (e.g. Stein, 1999; Toda et al., 2002). On the other hand, weak but significant interactions can be found between activities that are rather distant from each other in both space and time (e.g. Tiampo et al., 2002). These phenomena indicate the existence of stress transfer through dislocations by faulting or quasi-static slipping. As such, the redistribution of stress is reflected in the background seismicity, which is especially sensitive in the microseismicity (Jimenez et al., 2006; Ogata, 2005). The fundamental concept is based on the relationship between the seismicity rate and the stress rate (Dieterich, 1994). Thus, we have focused our attention on pattern changes of the background microseismicity, anticipating its possible relationship to a preparatory process of a major earthquake. One well-known pattern of the seismicty change in the approach to a critical stage is seismic quiescence. While recent reports mainly provided by the Wyss' group (Wyss et al., 1981; Wyss, 1986; Wyss and Habermann, 1988; Wiemer and Wyss, 1994, 1997) appear 


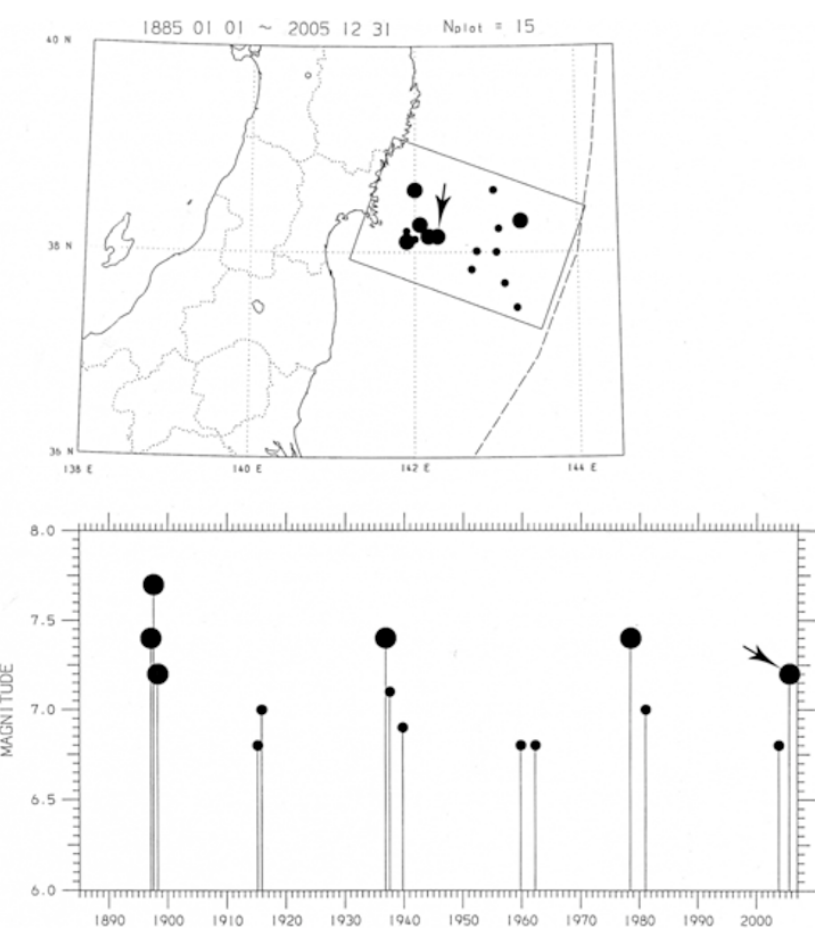

Fig. 1. Epicenters and time sequences of earthquakes of $M=6.8$ and greater that occurred in the focused area off Miyagi Prefecture. The thrust earthquakes on the plate boundary and the upper one between double-layered activities within the subducted Pacific slab are sampled, based on the Utsu and JMA catalogues. The arrow indicates the $\mathrm{M}=7.2$ event on 16 August 2005. The broken line is a trench axis. The large (small) solid circles are earthquakes greater than (less than) $\mathbf{M}=7.2$; these exhibit quasi-periodicity with intervals of 36 years (greater than $\mathrm{M}=7.2$ ) and about 21 years (less than $\mathrm{M}=7.2$ )

to be convincing, very little explanation has been given of its mechanism on a physical basis, with the exception of a few attempts (e.g. Matsumura, 2005a). In contrast, what we notice here is characteristic activation that could be detected preceding the two recent $M=7$ earthquakes.

\section{Procedure to Delineate the Change in Seismic- ity Rate}

The procedure is fundamentally the same as that used in the previous investigations conducted in the Tokai region by Matsumura (Matsumura, 2005b). Recent developments in observations have made it possible to examine detailed features of microearthquake occurrences throughout the whole of Japan, and this paper focuses on whether or not a preparatory process appears in the microseismicity preceding a major event. A delineated map of seismicity-rate changes was created by simply comparing earthquake frequencies during the study period with those in the previous period, with the latter used as a standard. Although ZMAP (Wiemer, 2001) is commonly utilized in such a procedure, it was not adopted here. Its z-value parameter, which is the ratio between the absolute difference and its standard deviation, strongly depends on the amount of data used, so it does not faithfully represent the absolute change in proportion to the seismicity rate itself. The microearthquake data were sampled from the unified JMA catalogue, which has a record of earthquakes with magnitude thresholds of $\mathrm{M}=2.0$ or less since 1997 . The sampling area is the rectangular zone de- picted in Fig. 1, where only those earthquakes occurring on the plate boundary and the upper part between the doublelayered clusters within the subducted Pacific slab have been extracted. These data points are distributed in a shallow depth around the trench axis on the east side and $80 \mathrm{~km}$ deep on the west side. At a magnitude threshold of $M=1.5$, there were a total of 10,000 earthquakes in the 9 years from 1997 through to 2005 . These were condensed to $80 \%$ through a declustering process in order to remove irregular seismic clusters generated by unusual activities, such as aftershocks and swarms. The declustering procedure adopted here is a simple way of grouping neighboring earthquakes within a box-type window in space and time. When at least three earthquakes are bundled, the other earthquakes, with the exception of the leading one, are removed. The window parameters selected were 7 days for the time span, and 3 $\mathrm{km}$ for the spatial distance. The number of earthquakes inside a $21-\mathrm{km}$ square frame were counted, compared with the standard for the preceding 5-year period and entered into a color-gradated distribution map. In such a comparison of both seismicities before and after an earthquake, there is usually a danger of producing a ghost of anomalous quiescense due to unusual activities not being removed from the standard period. However, the focus here is not quiescence, but activation, so this is not a problem.

\section{Characteristic Activation of Seismicity}

Figure 2 presents successive shots of the changes in seismicity pattern as observed every half year. The seismicity rate for the examined period of 1 year is compared with that for the standard period of the preceding 5 years. The exception is stage 1 , where the standard period is taken from the beginning of 1997 untill the end of 2001, the last portion of which overlaps with the study period. Red (blue) areas correspond to activation (quiescence) of the seismicity. Numbers on the index bar are percentages. The activated area moves from stage to stage, and it appears near the east region (along $143^{\circ} \mathrm{E}$ ) in stage 2 , becomes denser through stages 3 to 5 and later extends westward through stages 6 to 8. As depicted in Fig. 1, the most recent sequence of major earthquakes off Miyagi prefecture comprises two $M=7$ earthquakes: $M=6.8$ on 31 October 2003, and the above-introduced $M=7.2$ on 16 August 2005. The former occurred in stage 4, and the latter in stage 8. Epicenter maps were superposed on the seismicity patterns in Figs. 3 and 4. The same map of the $M=6.8$ event (solid triangle) and its after-sequence during the following month is overlaid onto both color patterns of stages 3 and 4 in the left and the right panels of Fig. 3. In the right panel, it seems natural that the red zone almost coincides with the seismicity distribution because the pattern of stage 4 is simply the result derived from the extracted event itself. However, it is not always natural that a similar pattern can also be seen in the left panel of stage 3 . This means that the activated zone in stage 3 was constructed in advance, covering the seismogenic zone of the following $M=6.8$ event and its aftersequence. The same situation is seen in Fig. 4, where the epicenter map of the $M=7.2$ event and its after-sequence is superposed onto both stage 7 (the left panel) and stage 8 (the right panel). The $M=7.2$ event occurred in stage 8 . In 

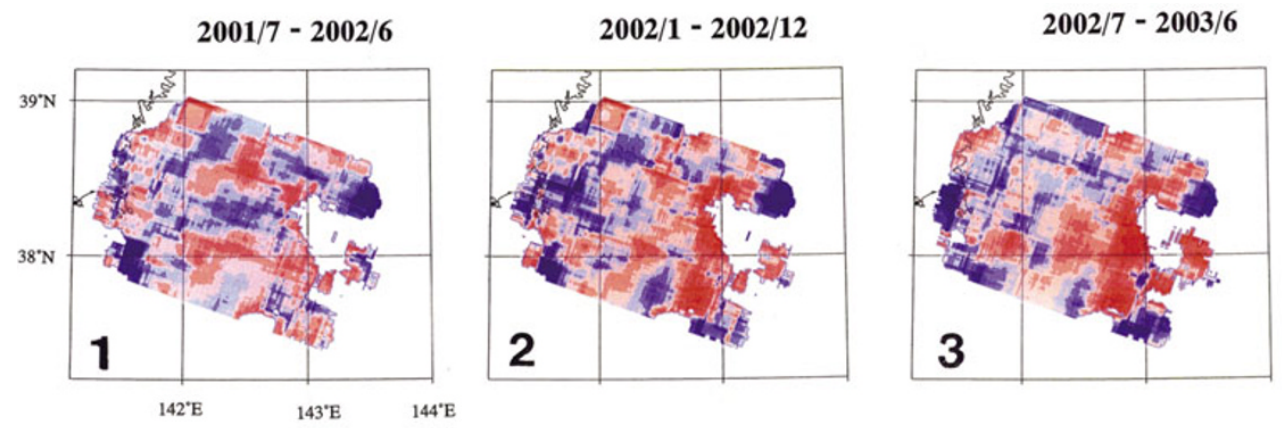

$2003 / 1-2003 / 12$

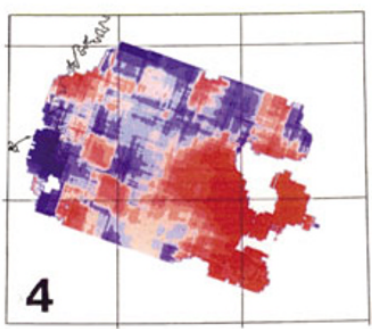

$2003 / 7-2004 / 6$
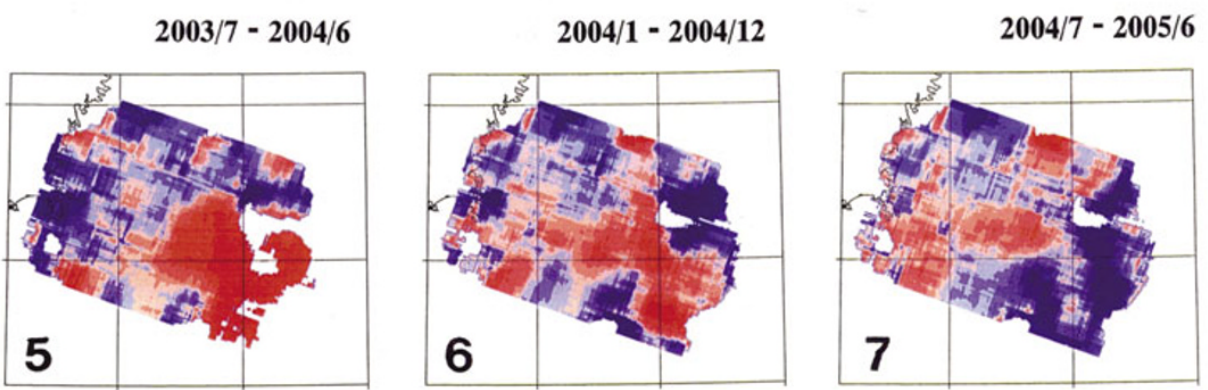

$2005 / 1-2005 / 12$
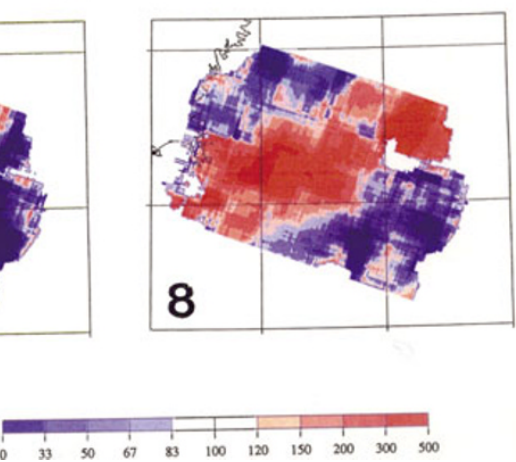

Fig. 2. Sequence of the changes in the seismicity pattern over a 1-year period, being moved every half year. Earthquakes of $\mathrm{M}=1.5$ and greater were sampled from the unified JMA catalogue. The investigated area is a rectangle $220 \mathrm{~km}$ long WNW to ESE and $140 \mathrm{~km}$ wide NNE to SSW. The earthquakes on the plate boundary and the upper one between double-layered activities within the subducted Pacific slab are extracted. The color gradations represent ratios of the seismic activity for each year compared to that for the 5-years period just prior to it, with the exception of the first one where the compared period is taken as the 5 years between 1997 through 2001. Blue corresponds to quiescence and red to activation. Numbers on the index bar are percentages of the ratio.

\section{$2002 / 7-2003 / 6$}

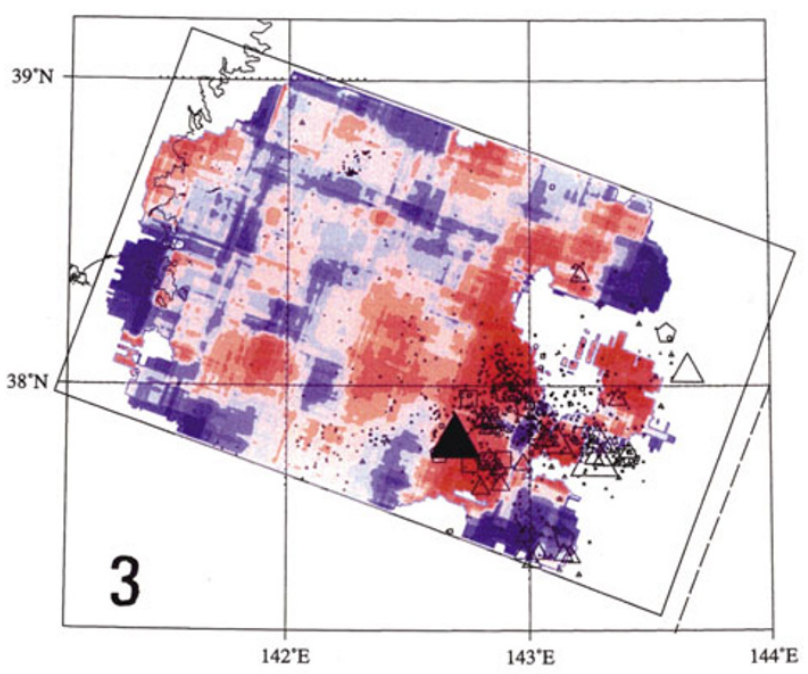

$2003 / 1-2003 / 12$

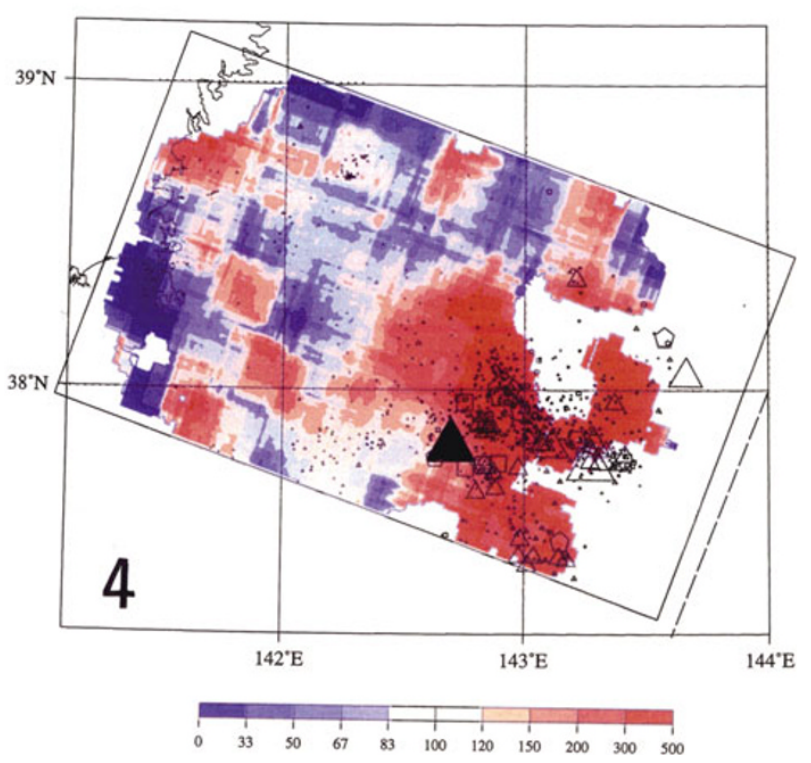

Fig. 3. Seismicity rate changes for stages 3 and 4 cited from Fig. 2. An M=6.8 earthquake occurred on 31 October 2003 , in stage 4 (right panel). The epicenters of $\mathrm{M}=6.8$ (the solid triangle) and its after-sequence during the successive 1 month are superimposed on both figures.

the left panel for stage 7, an activation in advance is once again found, covering the seismogenic zone of the following events. It should be noticed that the northeastern portion (around $38.5^{\circ} \mathrm{N}, 143.2^{\circ} \mathrm{E}$ ) was also assigned as an acti- vated zone in stage 7 , where induced events comprising two $M=6$ earthquakes happened about 2 weeks after the $M=7.2$ event. Thus, we conclude that the activation of the seismic activity predicted the rupture area of the subsequent $M=7$ 

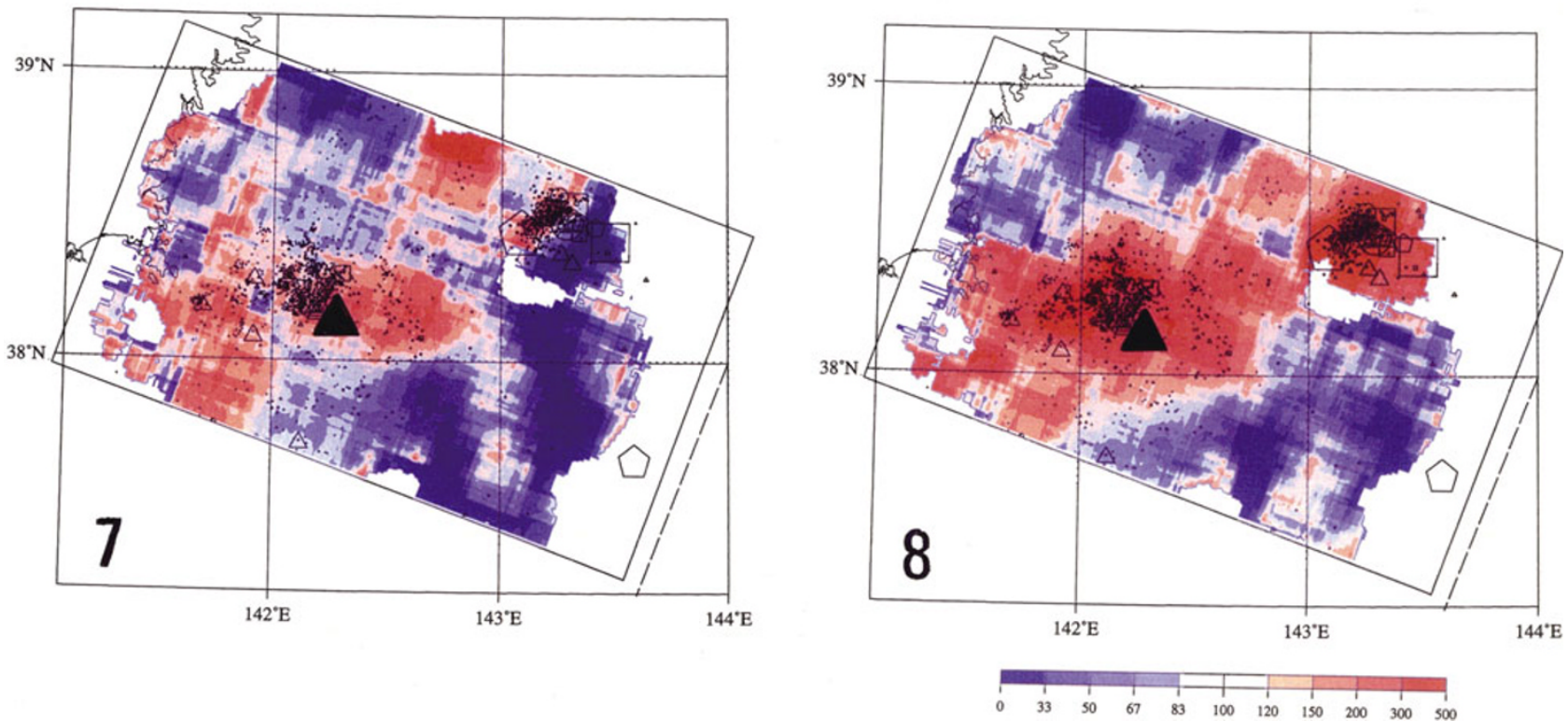

Fig. 4. Figures similar to Fig. 3 for stages 7 and 8 of Fig. 2. An M=7.2 earthquake occurred on 16 August 2005, in stage 8 (right panel). The epicenters of $\mathrm{M}=7.2$ (the solid triangle) and its after-sequence during the successive 1 month are superimposed on both figures.
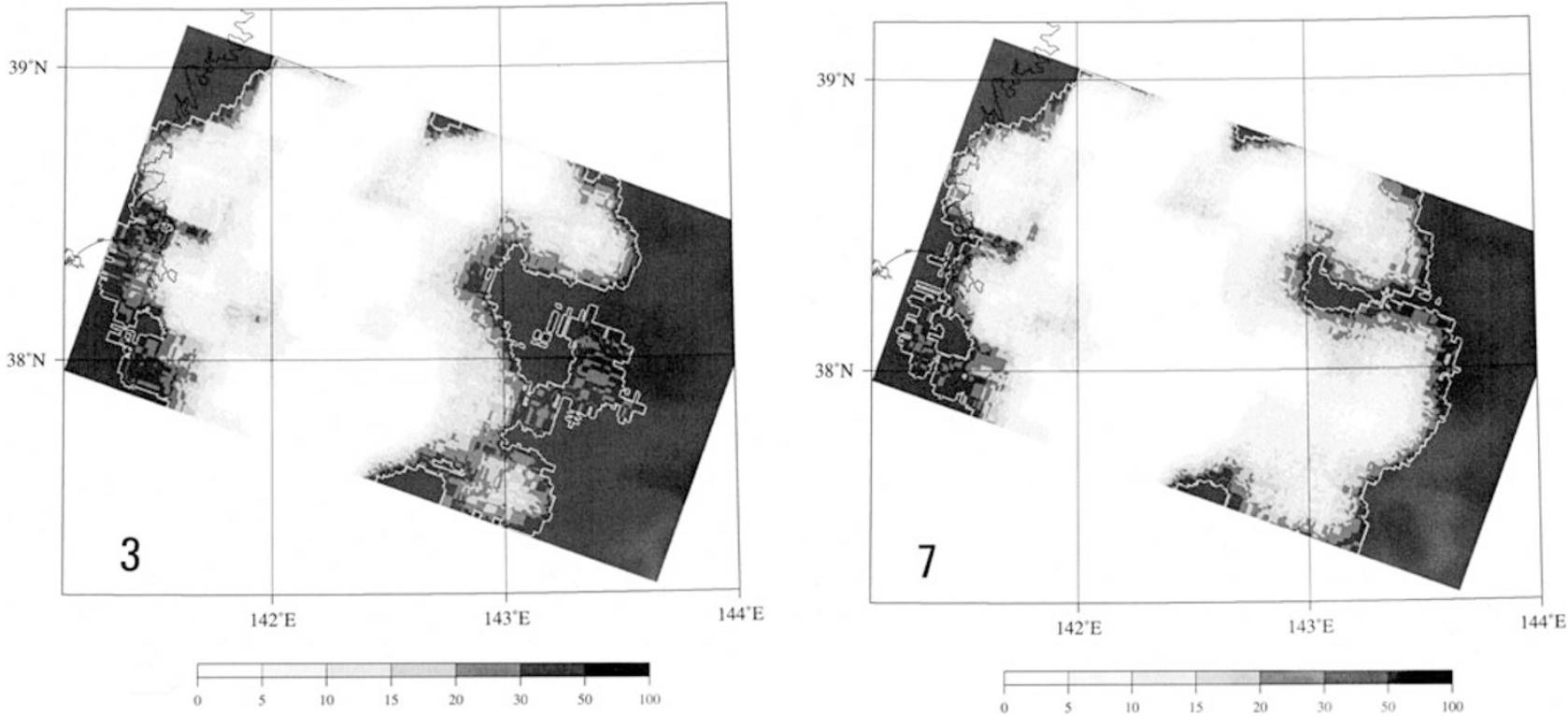

Fig. 5. Black-and-white gradations represent the significance level in a probability that the estimation of the activation exceeding $150 \%$ is accidental due to statistical fluctuation. The left (right) panel displays level distributions for stage 3 (stage 7). Notice that most of the activated areas (red zone) of stages 3 and 7 in Fig. 3 and Fig. 4 are placed within the significance level of less than 15\%.

events very well.

As mentioned, the ZMAP technique was avoided because it was inadequate for the present purpose. This decision, however, requires a test of the robustness of the results derived from the present procedure as follows. First, the statistical significance of the results was checked. The blackand-white patterns in Fig. 5 represent the statistical significance evaluated under a null hypothesis that the results of stage 3 and stage 7 are quite accidental due to statistical fluctuations. The numbers indicate the significance level in percentage for a $150 \%$ increase in the the frequency due to simple Poissonian fluctuations. The white zone corresponds to an area indicating a good significance level. It is obvious that most of the red zone in Figs. 3 and 4 falls within the level of less than $15 \%$ for both stage 3 (left panel) and stage 7 (right panel). The next check was for the general robustness of the results. The most serious problem in an analysis of microseismicity is the stability of the observation. The detection capability of microearthquakes in the JMA catalogue was not always stable during the entire study period. In a practical sense, it is difficult to ensure the completeness of detection for $M=1.5$ events, especially 

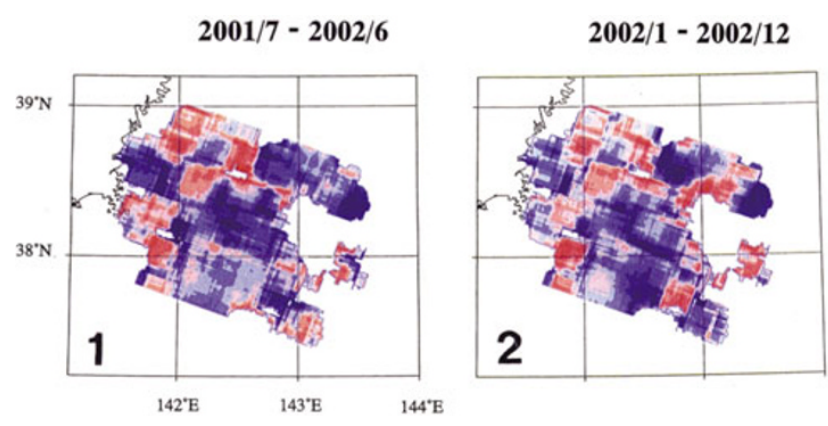

$2003 / 7-2004 / 6$

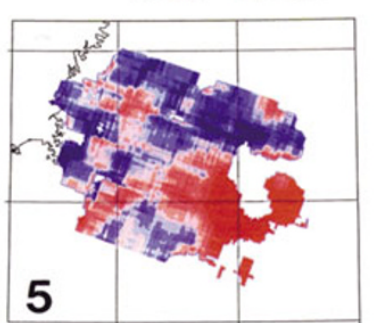

$2004 / 1-2004 / 12$

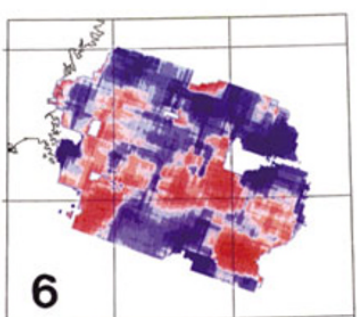

$2002 / 7-2003 / 6$

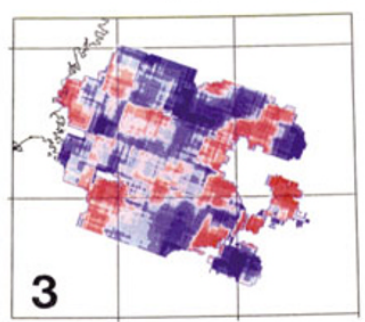

$2004 / 7-2005 / 6$

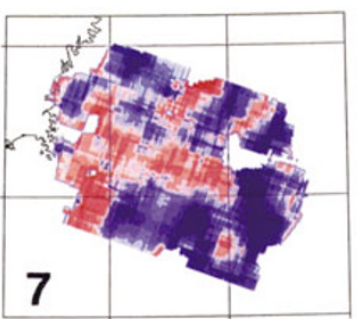

$2003 / 1-2003 / 12$

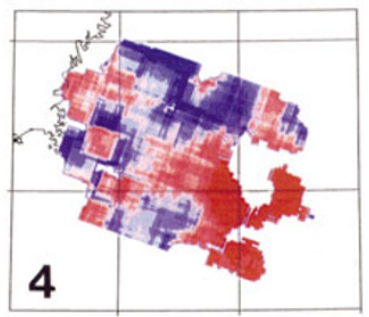

$2005 / 1-2005 / 12$

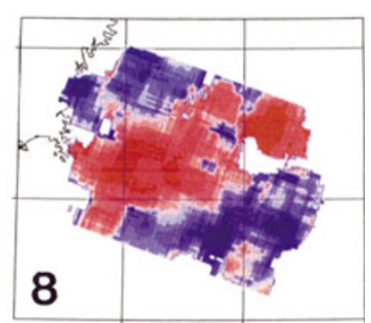

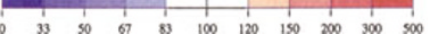

Fig. 6. Figures similar to Fig. 2 obtained by raising the magnitude threshold from M1.5 to M2.0. Their temporal variations essentially resemble those of Fig. 2, indicating that the activity pattern change of the seismicity is almost independent of the magnitude threshold, in spite of an extreme data reduction to one half of the original.

for earthquakes occurring far from the coast. Although the procedure utilized for treating the seismicity rate in the period between just before and just after the event mitigates this problem to a certain degree, it is difficult to assure a general consistency in the results. Consequently, a robustness test was conducted by drawing a picture similar to that of Fig. 2 but with the magnitude threshold increased from $M=1.5$ to $M=2.0$. The result is given in Fig. 6 , where the patterns very much resemble those in Fig. 2, with the one exception that activations in stage 3 are somewhat unclear compared to those in Fig. 2. Since the total amount of data used was only about one half that of Fig. 2, the robustness is still considered good enough to support our conclusion. The rupture area of the imminent $M=7$ earthquakes was indicative of activation of the background microseismicity.

\section{Discussion and Conclusion}

Dieterich (1994) proposed a theoretical formalism based on the rate-and-state constitutive friction law (Ruina, 1983) to prove that changes in the seismicity rate are in proportion to the stress rate. Based on this concept, the result discussed above implies that the rupture area of the $M=7$ earthquake has a relatively higher stress rate during the period preceding the final breakage than the remaining area. A rational and very comprehensible hypothesis explaining such a situation is the 'chain reaction model' presented by Matsuzawa's group (Matsuzawa et al., 2004). Analyzing the relationship between the seismicity-pattern change and the activity of repeating earthquakes on the plate boundary around the northeastern area of Japan, they developed the hypothesis that stress transfer caused by a quasi-static slip breaks small asperities in regular succession. This re- sults in a concentration of the stress on a larger asperity, which finally will be ruptured as a major earthquake. In the current analysis, all of the $M=7$ and $M=6$ earthquakes belonging to the focused sequence are regarded to be of the interplate thrust type according to their focal mechanisms (JMA, 2004, 2005). Most of the background microseismicity, however, is considered to occur not on the plate boundary, but within the subducted slab. Igarashi et al. (2003) reported that the regular repeating earthquakes are not distributed around the far off-coast area, where the present $M=7$ events occurred. As a result, the original chain reaction model is not directly applicable to the present situation.

Based on this evidence, the following modified hypothesis is proposed. Several spots exist on the seismogenic zone of the interplate earthquakes that are of a relatively higher strength compared with their surroundings, and these are the asperities. Such an arrangement of asperities resembles the situation proposed by Matsuzawa et al. (2004). However, the differences we found that deviate from their hypothesis suggest that the remaining area is not stablesliding, but locked in an early stage of stress accumulation. In that case, the whole area, including both the asperities and the remaining areas, is stressed at the same rate. At a critical stage, when the absolute stress exceeds the strength of the remaining area, a quasi-static slip will start to transfer stress, raising the stress rate on the asperities. Such a concentration of stress on the asperities should activate the background microseismicity within the slab just beneath the asperities prior to their final breakage. This will result in preparatory changes in microseismicity, as depicted in Figs. 3 and 4. 
This hypothesis may be only one possible explanation. However, if this is the most probable case, it at least enables us to predict a zone of imminent rupture. For example, several red spots remained still unbroken in both stages 7 and 8 of Fig. 4, one lying midway between two major events (around $38.2^{\circ} \mathrm{N}, 142.6^{\circ} \mathrm{E}$ ), another near the northern side (around $38.7^{\circ} \mathrm{N}, 142.8^{\circ} \mathrm{E}$ ) and a third near the southern side (around $37.9^{\circ} \mathrm{N}, 141.8^{\circ} \mathrm{E}$ ). It is not certain whether or not these spots will be broken soon, but at least it should be noted that they are still exposed to a relatively higher stress rate. In addition, it is significant that the major asperities of the 1936 and the 1978 off Miyagi Prefecture earthquakes (Yamanaka and Kikuchi, 2004) are not placed in the present red zones. Although this does not necessarily mean that the level of absolute stress is low at the present time, when the forewarned $M=7.5$ earthquake is about to occur, its time and place of failure might be indicated by a significant increase in the rate of microseismicity.

Acknowledgments. We would like to thank K. F. Tiampo and another anonymous reviewer for their valuable comments, which led our manuscript to be well revised. We utilized the GMT package created by Wessel and Smith (1995), with help from T. Mashiko.

\section{References}

Dieterich, J., A constitutive law for rate of earthquake production and its application to earthquake clustering, J. Geophys. Res., 99, 2601-2618, 1994.

Earthquake Research Committee, Reports on probabilistic evaluation map for seismic ground motion in Japan, 213 pp, 2005a (in Japanese).

Earthquake Research Committee, Earthquake off-shore of Miyagi prefecture on August 16, 2005, http://www.jishin.go.jp/main/index-html, $2005 \mathrm{~b}$.

Igarashi, T., T. Matsuzawa, and A. Hasegawa, Repeating earthquakes and interplate aseismic slip in the northeastern Japan subduction zone, $J$. Geophys. Res., 108(B5), 2249, doi:10.1029/2002JB001920, 2003.

Japan Meteorological Agency, Earthquake of M6.8 off Fukushima prefecture on October 31, 2003, Rep. Coord. Comm. Earthq. Pred., 71, 246251, 2004 (in Japanese).

Japan Meteorological Agency, An outlook of seismic activity in Japan, 2005/8-2005/9, Newslet. Seismol. Soc. Jpn., 17, 19-23, 2005 (in Japanese).
Jimenez, A., K. F. Tiampo, S. Levin, and A. M. Posadas, Testing the persistence in earthquake catalogs: The Iberian Peninsula, Europhys. Lett., 73, 171-177, 2006.

Matsumura, S., Why does the precursory change of seismicity rate tend to be quiescence?, Zisin, 57, 441-444, 2005a (in Japanese).

Matsumura, S., Seismic activity changes progressing simultaneously with slow-slip in the Tokai area, Tectonophysics, 417, 5-15, 2005b.

Matsuzawa, T., N. Uchida, T. Igarashi, T. Okada, and A. Hasegawa, Repeating earthquakes and quasi-static slip on the plate boundary east off northern Honshu, Japan, Earth Planets Space, 56, 803-811, 2004.

Ogata, Y., Detection of anomalous seismicity as a stress change sensor, $J$. Geophys. Res., 110, B05S06, doi:10.1029/2004JB003245, 2005.

Ruina, A., Slip instability and state variable friction laws, J. Geophys. Res., 88, 10359-10370, 1983.

Seno, T., On the earthquake expected off the Miyagi prefecture, Rep. Coord. Comm. Earthq. Pred., 21, 38-41, 1979 (in Japanese).

Stein, R. S., The role of stress transfer in earthquake occurrence, Nature, 402, 605-609, 1999.

Tiampo, K. F., J. B. Rundle, S. McGinnis, and S. J. Gross, Eigenpatterns in southern California seismicity, J. Geophys. Res., 107(B12), 2354, doi:10.1029/2001JB000562, 2002.

Toda, S., R. S. Stein, and T. Sagiya, Evidences from the AD 2000 Izu islands earthquake swarm that stressing rate governs seismicity, Nature, 419, 6902, 58-61, 2002.

Wessel, P. and W. H. F. Smith, New version of the Generic Mapping Tools released, Eos Trans. AGU, 76, 329, 1995.

Wiemer, S., A software package to analyze seismicity: ZMAP, Seism. Res. Lett., 72, 374-383, 2001.

Wiemer, S. and M. Wyss, Seismic quiescence before the Landers $(M=7.5)$ and Big Bear $(\mathrm{M}=6.5) 1992$ earthquakes, Bull. Seismol. Soc. Am., 84, 900-916, 1994.

Wiemer, S. and M. Wyss, Mapping the frequency-magnitude distribution in asperities: An improved technique to calculate recurrence times?, $J$. Geophys. Res., 102, 15115-15128, 1997.

Wyss, M., Seismic quiescence precursor to the 1983 Kaoiki $(\mathrm{Ms}=6.6)$, Hawaii, earthquake, Bull. Seismol. Soc. Am., 76, 785-800, 1986.

Wyss, M. and R. E. Habermann, Precursory quiescence before the August 1982 Stone Canyon, San Andreas fault, earthquakes, Pageophysics, 126, 333-356, 1988.

Wyss, M., F. W. Klein, and A. C. Johnston, Precursors to the Kalapana M=7.2 earthquake, J. Geophys. Res., 86, 3881-3900, 1981.

Yamanaka, K. and M. Kikuchi, Asperity map along the subduction zone in northern Japan inferred from regional seismic data, J. Geophys. Res., 109, B07307, doi:10,1029/2003JB002683, 2004.

S. Matsumura (e-mail: shozo@bosai.go.jp) 